\title{
Ameaças à profissão docente no brasil: desafios ao ensino de Ciências e Biologia em debate ${ }^{1}$
}

\author{
Threats to the Teaching Profession in Brazil: \\ Discussing Challenges to Science and Biology Education
}

\author{
Maicon Azevedo* \\ Rodrigo Cerqueira do Nascimento Borba** \\ Sandra Escovedo Selles***
}

\begin{abstract}
RESUMO: O presente texto apresenta e discute ameaças à docência relacionadas ao ensino de Ciências e Biologia no Brasil. Partindo das reflexões de Michael Apple (2001; 2015; 2017) sobre as alianças e projetos de controle da profissão docente que têm unido neoliberais e conservadores em pautas compartilhadas, contextualizamos tentativas de regulação do trabalho pedagógico com temas sensíveis aos conversadores e desafios para essas disciplinas escolares em face do cenário atual. Neste sentido, este estudo objetiva interpretar elementos e mensurar possibilidades de constituição de práticas pedagógicas democráticas, múltiplas, inclusivas e capazes de despertar o interesse e o encantamento nos estudantes. $\mathrm{O}$ artigo toma como base estudos acerca da abordagem de educação sexual nas aulas de Ciências e Biologia e a influência de vertentes cristãs conservadoras sobre o ensino de Origem da vida e Evolução Biológica na Educação Básica. Os estudos desenvolvidos analisaram a temática reprodução sexual humana em livros didáticos e a legislação que tornou obrigatório, no estado do Rio de Janeiro, o ensino religioso na forma confessional. O cruzamento destes estudos produziu dados de pesquisas que apontam e debatem os retrocessos no que tange à educação sexual e ao ensino da origem e da história dos seres vivos no planeta em bases evolutivas. Nesse bojo, cabe advertir que a frágil laicidade do Estado e dos sistemas educacionais têm se colocado como um fator relevante para a consolidação do comprometimento democrático do ensino de Ciências e Biologia.

Palavras-chave: conservadorismo; educação em ciências; currículo.
\end{abstract}

ABSTRACT: The paper presents and discusses threats to the Brazilian education related to the teaching of school subjects science and biology. The article is based on the reflections of Michael Apple (2001; 2015; 2017) regarding the alliances and projects to control the teaching profession that brought neoliberals and conservatives together in shared compromises. Therefore, the study aims to discuss possibilities for constituting democratic, multiple and inclusive pedagogical practi-

10 artigo é parte das reflexões trazidas pelo desenvolvimento dos projetos de pesquisa intitulado "Perspectivas curriculares e históricas para o estudo da disciplina escolar Biologia" e "Práticas docentes, comunidades disciplinares e produção da disciplina escolar: memórias de professores de Biologia", com recursos do CNPq.

* Professor do Centro Federal de Educação Tecnológica Celso Suckow da Fonseca. Doutor em Educação pela Universidade Federal Fluminense. E-mail: maiconbio@gmail.com ORCID: http://orcid.org/0000-00017699-6877

** Professor do Departamento de Ciências Biológicas do Instituto Superior de Educação Anísio Teixeira da Universidade do Estado de Minas Gerais. Doutorando no Programa de Pós-Graduação em Educação da Universidade Federal Fluminense. E-mail: rodrigocnb@gmail.com ORCID: http://orcid.org/0000-00024504-5793

*** Professora Titular da Faculdade de Educação e do Programa de Pós-Graduação em Educação da Universidade Federal Fluminense. Doutorado no Center for Science Education - University of East Anglia. É bolsista 1-C de Produtividade no CNPq e Cientista do Nosso Estado pela FAPERJ. E-mail:escovedoselles@gmail.com ORCID: http://orcid.org/0000-0002-7921-0478 
ces capable of rising interest and enchantment in students. Mainly, the article focuses on attempts to regulate teaching not only from the neoliberal but also from conservative groups that challenge these two school subjects. Research data from studies developed previously by the authors are discussed, showing setbacks on issues regarding sexual education and the teaching of evolution in Brazil. As a result, the article highlights that the fragile secularity of the State and of the educational systems has become a relevant factor to be addressed for the consolidation of a democratic commitment to science education.

Keywords: conservatism; science education studies; curriculum.

\section{Introdução}

Coronavírus. Ensino remoto. Negacionismo científico. Terraplanismo. Fake news. Hidroxicloroquina. Ivermectina. Pós-verdade. Enquanto militares comandam a saúde do país e teólogos capitaneiam as diretrizes educacionais, o binômio "ordem unida" e "joelho no chão" torna-se naturalizado dentro de um alegado "novo normal" que invisibiliza tragédias e catástrofes humanitárias e ambientais. Neste momento, no angustiante cenário de pandemia de COVID-19, questões que desafiam a formação e o trabalho docente e interpelam professores e investigadores do campo do Ensino de Ciências e Biologia se agudizam, jogando ainda mais incertezas sobre uma profissão que se constrói e se reconstrói sucessivamente ao longo de sua história: que sentidos produzem o ensino de Ciências e Biologia quando seus conteúdos plurais e tão diversos entre si, ganham, em contradição, protagonismo e rejeição? Que potência carregam as seleções curriculares das disciplinas escolares aqui focalizadas frente a um cenário que exalta o conhecimento - e os modos de proteção e tratamento contra o agente infeccioso - e ao mesmo tempo os despreza - em um cenário mundial de negação da ciência e de contínuo desprestígio da docência?

No quadro atual da pandemia, jogados a posições de Sísifos, docentes de Ciências e Biologia de escolas públicas e particulares, por força de seus gestores, abrem mão da docência. Entregam-se a produzir aulas virtuais, como se estivessem a acreditar que esta profissão pudesse desinventar a interação com seus alunos e seguir depositando conteúdos em suas mentes ao final de um semestre mal iniciado.

Se a pandemia coloca esses desafios, não se pode esquecer que as realidades brasileiras vêm sendo atravessadas por drásticas consequências produto dos desinvestimentos históricos nas políticas públicas de acesso à saúde e à assistência de qualidade a seus habitantes. Na educação, após vislumbrar alguns caminhos possíveis fruto de investimentos de governos progressistas, o quadro desolador retomou com maior intensidade desde 2016, após o impeachment de Dilma Rousseff. No governo que lhe seguiu os "reformadores empresariais" (FREITAS, 2012) disputaram as políticas educacionais com o acolhimento do Ministério da Educação.

A necessidade de distanciamento social que força milhões de brasileiros à reclusão em suas casas pelo perigo de contágio pelo vírus SARS-Cov-2, o novo coronavírus, tem provocado efeitos econômicos e sociais que amplificam o quadro educacional que antecedeu a pandemia. Com salas de aulas vazias, a maioria dos estudantes brasileiros divide seu exíguo espaço doméstico com as incertezas de suas famílias, em contraste com outros, cujos indicadores de moradia não guardam parâmetros de comparação. Se com estes compartilham incertezas do que lhes espera, certamente suas angústias são também desafios postos à docência.

Assim, a realização de um exercício analítico que debata desafios e oportunidades para o ensino de Ciências e Biologia no contexto brasileiro precisa considerar que não sabemos ao certo 
como se construirão os processos formativos no futuro pós-pandemia, nem nas escolas, nem nas universidades. Porém, certamente teremos que lidar com o excedente de angústia colocado sobre os sistemas educativos. Por isso, neste texto, buscamos interpretar elementos que despontam no tempo presente para tentar mensurar algumas possibilidades, inclusive futuras, de constituição de práticas pedagógicas mais democráticas, múltiplas, inclusivas e capazes de despertar o interesse e o encantamento nos estudantes em aulas dessas disciplinas escolares.

O artigo está organizado da seguinte forma: primeiro apresentamos uma análise panorâmica de inquietações que vêm se avolumando no campo do Ensino de Ciências e Biologia no Brasil. Em seguida, discutimos especificamente os ataques do conservadorismo aos currículos e às disciplinas escolares Ciências e Biologia em nosso país. Nas seções posteriores, trazemos elementos de pesquisas que realizamos para um debate mais contextualizado sobre as consequências das ofensivas reacionárias ao trabalho com conceitos e conteúdos caros a essas disciplinas, como educação sexual e evolução biológica. Por fim, à guisa de conclusão, suscitamos algumas ponderações e considerações finais.

\section{Questões exercidas sobre o ensino de Ciências e Biologia na atuali- dade}

Vivemos no Brasil, assim como em outros países da América Latina e do mundo, o fenômeno intitulado por Michael Apple $(2001 ; 2015 ; 2017)$ como restauração ou modernização conservadora. De um lado, a substituição gradativa da responsabilidade do Estado em produzir e gerir políticas educacionais dá lugar à presença mais efetiva de corporações e fundações privadas e estatais. Por outro lado, o avanço de grupos conservadores também disputa as políticas educacionais para interferir nas decisões do Estado. Utilizando a retórica da liberdade de escolha, o fenômeno se caracteriza por uma combinação entre adotar as práticas da "nova" cultura advinda dos mercados globalizados (representado pelas medidas de responsabilização ou accountability e os discursos sobre eficiência) unida à "velha" cultura de disciplinarização dos indivíduos, de seus corpos, suas práticas e desejos - suscitado por pautas morais conservadoras e tradicionais.

Segundo Stephen Ball (2004), a partir dos anos 1990, intensas modificações em políticas educacionais e práticas docentes que se deram em nível mundial produziram reflexos na América Latina e, obviamente, no Brasil. Dentre essas mudanças, a invasão da racionalidade do mercado produtivo produz alterações em hábitos, práticas e culturas nos diversos setores públicos, incluindo o educacional. Ball documenta esta mudança, reconhecidamente de caráter neoliberal, quando esta ideologia redefine a função de um Estado provedor e responsável pelas suas instituições e reduz seu funcionamento. Neste reordenamento globalizado, as relações entre Estado, capital e sua população enfatizam o papel estatal regulador, que minimiza investimentos, delega e distribui a responsabilidade sobre a eficiência das instituições públicas aos seus trabalhadores e gestores. Ball (2004) chama esta nova cultura de performatividade.

Nas políticas educacionais, a cultura de performatividade se impõe externamente sobre a escola pretendendo controlar docentes e estudantes por meio da padronização curricular, apoiadas em justificativas da falência do sistema público, como meio de "otimizar" os gastos e "prestar" contas à sociedade, além de prover com igualdade o ensino para todos os alunos. Iniciado na década de 1990 em países capitalistas que assumiram a condução da ideologia neoliberal, como os Estados Unidos de Ronald Reagan e o Reino Unido de Margareth Thatcher, mas estendido gradativamente 
a inúmeros países, dos quais o Brasil também se inclui, o controle dessas políticas recai sobre definições centralizadas de currículo, detalhando o que deve ser ensinado para que sistemas de avaliação em massa, obviamente externos à escola, verifiquem o cumprimento do currículo proposto.

Tais resultados não significam apenas a divulgação do quanto os alunos e as alunas aprenderam, mas expõem um modelo de desempenho de suas escolas e seus docentes, atribuindo valores e produzindo ranqueamentos escolares. Desnecessário dizer que, quando expostos a escrutínios públicos deslocados de seus contextos de atuação, os professores se sentem desvalorizados e inseguros nesta cultura performática. Deste modo, a experiência docente é secundarizada tanto na produção do currículo e da avaliação quanto nos resultados amplamente publicizados.

Na última década em particular, políticas públicas para a educação brasileira têm sido projetadas e implementadas em acordo com as soluções gerencialistas formuladas por meio de análises embasadas por perspectivas mercadológicas. Por sua vez, muitos arrogam que a solução para os problemas educacionais do país residiria em um "retorno" a padrões intelectuais mais exigentes e a uma "cultura comum tradicional", centrada fundamentalmente na aprendizagem conceitual de forma neutra, conforme examina Apple (2015). Assim, líderes religiosos fundamentalistas e políticos com posturas autoritárias, de modo orquestrado, vêm continuamente produzindo ações, fortalecendo discursos que afetam os tempos e os espaços educativos e impondo restrições à liberdade docente.

Como assinala Apple $(2015$; 2017), a vontade de regressar a um passado romântico e idealizado de família e escola tem sido acompanhada por medidas que resgatam facetas do darwinismo social, garantem o aumento da competitividade entre as pessoas, promovem maior lucro para bancos e grandes empresas, aprofundam a desregulamentação do mercado e acentuam a flexibilização das leis trabalhistas, precarizando relações de emprego. No âmbito curricular, a restauração conservadora também tem produzido efeitos diversos com propostas de reformas educacionais que injetam determinadas visões sobre o que seria uma "sociedade justa" e um "bom aluno" nos cotidianos escolares (APPLE, 2001). Compartilhando a retórica da liberdade, conservadores e neoliberais se articulam para defender a regulação comportamental e conceitual por meio de currículos nacionais e sistemas de avaliação em larga escala, intensificando processos de conversão do capital econômico e social em cultural.

No Brasil, documentos curriculares unificadores e homogeneizadores das experiências educativas para as três etapas da Educação Básica formam a Base Nacional Comum Curricular (BNCC). Tanto a Educação Infantil, quanto o Ensino Fundamental e o Ensino Médio contam com padronização compulsória acerca do que deve ser ensinado, aprendido e avaliado ao término de cada ano de escolarização. Organizada em torno de competências gerais, competências específicas, unidades temáticas, objetos de conhecimento e habilidades, a BNCC representa o ápice das políticas centralizadas de currículo que começaram a ser instauradas no final da década de 1990, quando Parâmetros Curriculares Nacionais (PCN) foram propostos.

Tal processo de forma alguma pode ser considerado um ato isolado ou obra do acaso. Este período é marcado pelo surgimento de políticas de centralização curricular em vários países do mundo. Em comum, testemunha-se o fortalecimento dos discursos e dos mecanismos de controle sobre os currículos escolares e de regulação da formação e do trabalho docente. Coadunadas ao movimento orquestrado por aqueles que Freitas (2012) nomeou como "reformadores empresariais da educação", as políticas de eficiência social para o currículo, que em uma perspectiva tradicional podem ser caracterizadas, ainda que com muitas nuances, pelo privilégio dado às ações de planejamento e avaliação, voltaram à tona. Essas políticas são agora materializadas nas habilidades e com- 
petências presentes na BNCC, que se traduzem em mecanismos sofisticados de prescrição e coerção sobre a profissão docente. Preservando algumas características do passado, o (neo)eficientismo carrega os conceitos de eficácia, eficiência, gestão e economia como estruturantes, além do desprezo pelo o que acontece nos plurais cotidianos das escolas.

Reforçando um viés tecnicista e pragmático para a Educação Básica brasileira, a BNCC se apoia na ideia de que existem "direitos de aprendizagem" que precisam ser resguardados a qualquer custo, bem como competências e habilidades que devem ser apropriadas e desenvolvidas por todo e qualquer estudante em território nacional. Evidenciando convergência entre essas políticas, uma Base Nacional Comum da Formação de Professores da Educação Básica" (BNCFP) também foi sugerida para padronizar os cursos de Licenciatura de todo o país e controlar a formação de professores.

Pela vinculação explícita entre BNCC e BNCFP, parece-nos que se constituem dispositivos curriculares que promovem gradual enquadramento da educação brasileira aos anseios neoliberais e neoconservadores, desalinhando discussões e práticas que permitiam abordagens pedagógicas plurais, elaboradas e referenciadas nos saberes e experiências cotidianas de estudantes e docentes. Dentre as temáticas mais vulneráveis ao silenciamento promovido pela aliança reacionária que se intensifica no Brasil, encontram-se os atravessamentos socioculturais que interpelam o ensino da biologia do corpo humano, os debates socioambientais que trazem a dimensão humana e social para as aulas de Ecologia e o ensino das teorias evolutivas, ameaçado pelo progressivo rompimento da laicidade do Estado.

Interpelando o corpo orgânico formado por conhecimentos morfofisiológicos sobre células, tecidos, órgãos e sistemas estão as questões de gênero e sexualidade, diversidade étnico-racial e socioambientais. Mesmo silenciadas nas linhas dos documentos curriculares, elas gritam, se fazem presentes e se tornam mais complexas no dia a dia da escola. Intermediadas por questões de saúde sobre o corpo humano, debates sobre culturas e identidades chegam para o ensino de Ciências e Biologia de forma negociada (BASTOS e ANDRADE, 2016), mas evidenciam tensões de difícil trato para muitos docentes .

\section{Ensino de Ciências e Biologia em devaneios ultraconservadores}

A aliança restauradora articulada por setores neoliberais e ultraconservadores, mesmo que não mostre pautas absolutamente iguais sugere sua complementaridade, e colocam ainda mais tensão sobre os professores de Ciências e Biologia, agora sob profundo escrutínio social. Sob o espectro da moralidade e da defesa de valores familiares, ainda que sempre questionáveis, diversos setores da sociedade fortalecem a ideia de que é preciso tomar esses valores como parâmetros para controlar o que se passa nas salas de aula.

Desrespeitando a legislação nacional máxima e agredindo um pacto de respeitabilidade mútua entre professores e estudantes, a autoridade docente se torna sitiada pelos inúmeros incentivos para que os alunos produzam gravações de áudios e vídeos de aulas. Talvez não seja preciso destacar a dimensão contraproducente e antipedagógica desse tipo de ação, uma vez que o ambiente beligerante incitado por atitudes perniciosas de descrença em relação à prática docente implode a confiança e a empatia constituintes das bases cognitivas dos processos de aprendizagem. Esses materiais serviriam como evidências para denunciar os professores junto aos canais jurídicos quando os docentes discutissem temas considerados controversos ou argumentassem sob óticas 
divergentes às do estudante ou de sua família. Mais uma vez, intenções obscuras se sobrepõem ao processo de aprendizagem inibindo o debate, atividade tão cara às atividades pedagógicas. Acrescida de mais uma privação, os docentes de Ciências e Biologia se perguntam como enfrentar desafios tão agudos, sobretudo porque estes não se coadunam com tempos de regime democrático.

Cabe dizer que esses desafios se agudizaram com a emergência de um movimento social brasileiro composto por pais que reclamavam do que diziam ser "interferência ideólogica" de professores ao ensinarem conteúdos considerados contrários a seus valores domésticos. Nestes se incluem, dentre tantos, a educação sexual e o ensino de evolução biológica. Assim, esse movimento passou a arrogar direitos de escolha sobre a educação escolar quando esses temas e outros correlatos são incluídos nas aulas. Com a retórica de defesa da família e dos valores sociais considerados coerentes com princípios cristãos, diversos segmentos, dentre eles muitos religiosos católicos e protestantes, se uniram para fundar o que se denomina "Movimento Escola sem Partido" (MESP).

A escolha deste título foi estrategicamente pensada para induzir afinidades, pois a não adesão ao MESP se desdobraria retoricamente em anuência direta a uma ideia que não agrada a maior parte das pessoas: a de uma escola partidária ou com partidarismos, defensora de uma vertente ideológica singular e específica sem espaço para diversidades de ideias. Sendo assim, o próprio nome dado ao movimento tornou-se instrumento de popularização do mesmo, comunicando-o de forma efetiva até aos mais incautos. Artimanha usada talvez para ocultar seu principal objetivo, o de acusar um partido posicionado dentro do espectro político de centro-esquerda, que governou o Brasil entre 2002 a 2016, de hipersexualizar os estudantes e de desenvolver o pensamento crítico, ao invés de ensinar conteúdos em perspectivas consideradas "neutras".

Criada em 2004 pelo advogado Miguel Nagib, os integrantes da organização que deu origem ao MESP estendem suas reivindicações para agregar parlamentares com o fim de alterar a Constituição Federal e a Lei de Diretrizes e Bases da Educação Nacional, vigentes no país desde a retomada democrática após o duro regime ditatorial civil-militar. Assim, parlamentares integrantes do MESP ou identificados com seus valores ultraconservadores propõem ao Congresso Nacional projetos de lei $^{2}$ (PL) para institucionalizar e nacionalizar os procedimentos coercitivos sobre os professores pelo Estado brasileiro.

O primeiro artigo do PL 7180/2014 pleiteia: "Esta lei disciplina o equilíbrio que deve ser buscado entre a liberdade de ensinar e a liberdade de aprender, no âmbito da educação básica, em todos os estabelecimentos de ensino públicos e privados do País". Ao que denominam "equilíbrio" inclui-se: o ensino de explicações criacionistas de fundo religioso em confronto com as teorias evolutivas cientificamente alicerçadas; a supressão dos debates sobre identidade, papéis e desigualdades de gênero na educação escolar, inclusive com remoção do termo "gênero" em documentos oficiais e materiais didáticos por julgarem que ele está comprometido com o que chamam "ideologia de gênero"; além disso, instaura-se a rejeição ao ensino de educação sexual, questionando sua abordagem como parte do currículo de Ciências e Biologia e responsabilizando-o pela hipersexualização dos estudantes e pela realização de práticas que atentam contra os valores morais, éticos e religiosos tradicionais (PENNA, 2017).

Assim, a disputa sobre o controle da escola se acentuou diante do processo de restauração conservadora (APPLE, 2015). Somando-se aos atores e grupos sociais privativos alinhados com a "economia de mercado" que defendem uma gestão empresarial e menos democrática para as ins-

2 Tratam-se de PLs diferentes que se reforçam e intensificam os dispositivos de vigilância e censura contra docentes. O primeiro PL foi o de número 7180/2014, seguidos pelos PLs 867/2015 e 246/2019. 
tituições escolares, podemos encontrar essa frente política conservadora que requer um Estado forte para controlar os sujeitos, defendendo apenas as "liberdades" que não possam ir de encontro aos seus pressupostos familiares e religiosos. Sob o argumento de uma necessária recuperação moral da sociedade, tais pressões e iniciativas se acirram dirigindo-se às salas de aulas. Apesar de divergirem sobre as exigências de controle do estado sobre a escola pública, esta oposição é relativa, pois a aproximação entre as lógicas que movem os grupos empresariais e os conservadores é reconhecida por Macedo (2016) como "zonas de equivalência entre elas, o que não significa dizer que não há também diferenças” (p. 509) em relação ao controle do currículo.

Com efeito, sem pretender neste artigo estender as considerações sobre o MESP, cabe a possibilidade de pensá-lo como um potente instrumento (neo)eficientista que se propõe a resgatar uma lógica racionalista de currículo, uma vez que restringe a ação do professor ao papel de instrutor, de um mero administrador de conteúdos. Tal visão possibilita a consolidação de mecanismos de accountability que se coadunam aos constrangimentos impostos pela BNCC, ao mesmo tempo em que conformam e alinham a profissão docente aos dispositivos e discursos da restauração conservadora (APPLE, 2015). Desta forma, a pressão realizada por esse movimento sobre a docência se soma aos muitos outros desafios impingidos ao ensino de Ciências e Biologia na atualidade. Especialmente porque oferece um manual aos estudantes para fundamentar denúncias contra seus professores quando reconhecerem que o que se ensina fere seus alegados direitos de apenas estudar o que é de acordo com os valores familiares ${ }^{3}$. Para isso revisitaremos trabalhos por nós desenvolvidos sobre as temáticas colocadas em xeque pelo MESP, em especial, a educação sexual e as teorias evolutivas.

Trazer análises de pesquisa sobre essas temáticas caras ao ensino de Biologia, permite recordarmos que os currículos nunca são neutros ou meras prescrições: são condicionados epistemológica, política, social, econômica, ética e esteticamente. Assim, ao refletir relações de poder, os currículos não são estáticos nem imunes a debates e conflitos em torno das questões que atravessam a sociedade e as ciências de referência. Tanto o currículo quanto às disciplinas escolares Ciências e Biologia são palco de disputas e negociações nos processos de seleção de conteúdos e métodos de ensino, e são atravessados, portanto, por interesses de grupos sociais e de instituições historicamente situadas. As próximas seções servirão para aprofundar esse entendimento de currículo e para adensar nossas reflexões acerca dos desafios e oportunidades colocadas ao ensino de Ciências e Biologia e seus docentes na atualidade brasileira.

\section{Educação sexual na mira do conservadorismo}

Para enfrentar os questionamentos acerca da abordagem de educação sexual nas aulas de Ciências e Biologia, desenvolvemos alguns estudos visando verificar em que medida esta temática estaria presente no intervalo de três décadas em materiais curriculares utilizados pelos professores em suas aulas. A escolha temporal se justifica porque o MESP acusa os educadores de estarem há 30 anos, desde a democratização brasileira, inundando as salas de aula de conteúdos ideologizados e contrários à moral cristã. Uma das motivações para os estudos a serem aqui apresentados são ações civis e de Estado a respeito da impropriedade da educação sexual, seguindo alegações do

\footnotetext{
${ }^{3}$ Na página oficial do ESP se encontra um breviário jurídico que orienta os modos de fundamentar a denúncia dos estudantes contra professores. Disponível em <https://www.programaescolasempartido.org/>. Acesso em maio de 2020.
} 
MESP na sua página oficial.

Como exemplo dessas ações, a denúncia feita por pais de alunos ao Ministério Público brasileiro afirma que um livro didático de Ciências ${ }^{4}$ aprovado e distribuído pelo Programa Nacional do Livro Didático (PNLD) ${ }^{5}$ abordaria conteúdos sobre corpo humano, sexualidade e gravidez na adolescência inapropriados para a idade de estudantes matriculados no $8^{\circ}$ ano do Ensino Fundamental, que tem idade mínima esperada de 13 anos. Mais recentemente, apostilas de ciências da rede municipal de São Paulo foram tiradas de circulação pelo atual prefeito por supostamente conterem apologia à "ideologia de gênero".

Diante desses exemplos, investigamos modos como a educação sexual vem sendo abordada em livros didáticos de Ciências e Biologia em um período histórico que compreende as décadas de 1990 à 2010, considerando que envolve três gerações de docentes destas disciplinas escolares. Esses estudos foram desenvolvidos apoiando-se em referenciais da teoria de currículo, estudos históricos sobre a disciplina escolar e a pedagogia crítica de Gert Biesta (2013). O propósito era investigar uma abordagem curricular contestada pelos conservadores e reafirmar o compromisso sociocultural e histórico dessa temática no ensino de Ciências para uma educação democrática, atenta às necessidades sociais e individuais dos estudantes.

Os estudos desenvolvidos analisaram a temática reprodução sexual humana em livros de Ciências e Biologia desde 1990 até 2010, utilizando critérios similares de escolha. Assim, um dos estudos focalizou sete livros didáticos de Ciências voltados ao $8^{\circ}$ ano $/ 7^{a}$ série $^{7}$ selecionados da biblioteca do Laboratório de Ensino de Ciências da Universidade Federal Fluminense ${ }^{8}$ (UFF). Em outro estudo, para examinar a questão na disciplina escolar Biologia, tomamos como objeto empírico imagens de 10 livros de Biologia publicados desde 1990 a 2010, utilizando como critério de seleção dos livros aqueles que continuam várias edições e por circularem na escola em algumas décadas.

Tais critérios expressam princípios de legitimidade desses materiais curriculares, conforme sugere Chopin (2004), para que a amostra seja considerada representativa para indicar tradições curriculares do ensino de Biologia. Assim, combinamos dois critérios: (i) livros de 1990 com autores comuns que continuam a ser publicados até a década de 2010, indicando que teriam sido utilizados por diferentes gerações de alunos; (ii) livros recomendados pelo PNLD. Do cruzamento destes critérios, terminamos por examinar livros de três autores que têm publicações desde a década de

4 Disponível em: <https://noticias.uol.com.br/cotidiano/ultimas-noticias/2017/04/01/pais-acionam-mppara-tirar-de-escolas-livro-com-ilustracao-de-orgaos-sexuais.htm>. Acessado em 31 de janeiro de 2020.

${ }^{5}$ O Programa Nacional do Livro Didático é uma política nacional do Ministério da Educação brasileiro de avaliação, aquisição e distribuição de livros didáticos publicados por diversas editoras para as escolas públicas de todos os níveis da escolaridade a cada três anos (BRASIL, 2012).

${ }^{6}$ Disponível em: <https://g1.globo.com/sp/sao-paulo/noticia/2019/09/03/doria-manda-recolher-livros-deciencia-que-fala-sobre-diversidade-sexual-nao-aceitamos-apologia-a-ideologia-de-genero.ghtml>. Acessado em 31 de janeiro 2020.

${ }^{7} \mathrm{O}$ uso da nomenclatura série ou ano escolar corresponde às mudanças de denominações deste estágio da escolaridade brasileira que atravessaram as décadas em foco. A escolha deste ano/série se deve ao fato de ser nesta etapa da escolaridade que o tema corpo humano vinha sendo tradicionalmente abordado na disciplina escolar Ciências. Atualmente, a BNCC rompeu com essa tradição curricular, diminuiu os conteúdos sobre corpo humano a serem trabalhados no Ensino Fundamental e os pulverizou por diferentes anos.

8 O Laboratório de Ensino de Ciências reúne docentes e estudantes da Faculdade de Educação da UFF interessados em investigar os processos de formação de professores de Biologia, Química e Física e suas ações pedagógicos na escolas e em outros espaços educativos. 
1990 e são recomendados pelo PNLD. ${ }^{9}$

Todos os livros de Ciências e Biologia analisados apresentam ilustrações gráficas de órgãos sexuais masculinos e femininos, de corpos nus ou de métodos contraceptivos. Em todas as obras o modo de tratar o corpo humano no ensino de Ciências e Biologia pode ser considerado como uma das tradições curriculares dessas disciplinas. Entretanto, afirmamos que se a prevalência de ilustrações anatômicas parece acentuar o modo fragmentado de apresentar o corpo humano, a seleção de imagens analisadas também mostra órgãos genitais em disposições não estáticas.

Diferente das imagens encontradas em Atlas de Anatomia, o que acentuaria sua fragmentação, esses órgãos encontram-se ilustrados com artefatos culturais (como dispositivos anticonceptivos), que sinalizam funções não unicamente reprodutivas ou de interesse médico. Ao incluir imagens de pênis eretos em que se colocam preservativos, ou em menor número nos livros analisados, diafragmas sendo introduzidos manualmente na vagina, os órgãos genitais femininos e masculinos podem ser estudados não como uma ferramenta biológica criada para a reprodução, mas no desempenho de atividades que incluem outros hábitos e valores humanos.

Ainda que não se possa dizer que se trata de uma abordagem integradora, a qual procura representar as interrelações entre fisiologia e estrutura, a inclusão desses artefatos nos órgãos sexuais, possibilita pontes com os aspectos psicológicos e sociais na discussão sobre o corpo humano. No conjunto de livros apresentados são contempladas finalidades educativas que não se reduzem ao enfoque biológico para ensinar a anatomia e a fisiologia da reprodução humana. Portanto, a presença desses artefatos culturais ao longo dos últimos 30 anos pode ter favorecido abordagens de temas como gênero e sexualidade.

Em outro empreendimento investigativo (BORBA e SELLES, 2019), vislumbramos uma série de mudanças na BNCC de Ciências orquestradas por influência de lideranças conservadoras. As pressões pelo silenciamento de debates sobre educação sexual e seus entrecruzamentos com questões de gênero e sexualidade se traduziram no corpo do texto apresentado na versão final do documento.

Como exemplo temos que na penúltima versão do documento, divulgada em abril de 2017, estava previsto dentro do conjunto de competências e habilidades a serem desenvolvidas "Selecionar argumentos que evidenciem as múltiplas dimensões da sexualidade humana (biológica, sociocultural, afetiva e ética) e a necessidade de respeitar, valorizar e acolher a diversidade de indivíduos, sem preconceitos baseados nas diferenças de gênero" (BRASIL, 2017, p.300 - grifo nosso). Porém, na versão final homologada, a habilidade prevista foi apenas "Selecionar argumentos que evidenciem as múltiplas dimensões da sexualidade humana (biológica, sociocultural, afetiva e ética)" (BRASIL, 2017a, p. $347)$.

Assim, não estipular na BNCC que as discussões sobre gênero sejam parte obrigatória da Educação Básica, além de materializar o conflito de grupos pelo controle do currículo, retira parte do respaldo legal de docentes e escolas que entendam a necessidade de abordar esse conteúdo, além de esvaziar as suas importância e legitimidade. Um desafio, portanto, é harmonizar a exploração pedagógica da dimensão biológica constitutiva da identidade sexual de forma associada aos debates sobre os papéis de gênero socioculturalmente atribuídos e em interface com discussões sobre direito sexual e direitos humanos que problematizem estereótipos e combatam preconceitos.

Tensionar as experiências sexuais para explorá-las de modo multidimensional e intercultu-

\footnotetext{
9 Na cultura escolar, os livros didáticos são identificados pela sua autoria, alternando nomes e sobrenomes dos autores.
} 
ral, para além do sexo biológico e entendendo as diferenças nas identidades sexuais e de gênero enquanto conhecimentos escolares, tem sido uma demanda colocada para professores de Ciências e Biologia. Nesse cenário, reflexões sobre as sexualidades que integram o conjunto de experiências humanas e escolares são suscitadas pelos próprios alunos a partir de óticas culturais, sociais e históricas distintas. Desse modo, qualquer homogeneização pretendida pelo conhecimento científico "neutro" da anatomia e da fisiologia humana é impossível, mesmo que preconizado por disposições curriculares e apresentado como padrão em materiais didáticos variados.

Esses achados dialogam com outro estudo que defende o quanto as questões sociais e culturais vêm interpelando abordagens exclusivamente biológicas, contando com a mediação das professoras e professores de Ciências e Biologia (VILELA e SELLES, 2015). Portanto, os resultados dos estudos sugerem que historicamente a abordagem da sexualidade tem estado presente nos currículos escolares oficiais, muito antes do ataque ultraconservador. Ao usar esses materiais curriculares, de algum modo os docentes eram lembrados de que precisavam estar ao lado dos estudantes para que atravessassem a adolescência, minimamente, com informações apropriadas, o que certamente influenciou os modos como a temática foi sendo trabalhada. Ao acolher essas demandas estudantis, a responsabilidade docente se coloca contra a alegação de que a abordagem da reprodução humana e da sexualidade é apenas responsabilidade da família.

\section{Origem e diversidade da vida: conflitos construídos pelo conserva- dorismo}

Assim como acontece na crítica ultraconservadora ao trabalho com educação sexual associado ao ensino da reprodução humana em aulas de Ciências e Biologia, a teoria da evolução tem sido alvo de ataques, especialmente do MESP. Cabe dizer, entretanto, que o questionamento da pertinência desta temática na escola já atravessou o século passado, em especial nos Estados Unidos, e continua no atual de forma intermitente. Embora sem parâmetros de comparação com as batalhas travadas no contexto educacional estadunidense no século passado, no Brasil, a questão surgiu mais fortemente nos anos 2000, em especial no Rio de Janeiro.

A crescente influência de vertentes cristãs conservadoras na educação brasileira tem impactado e interpelado professores de Ciências e Biologia que precisam cada vez mais lidar com com interpretações criacionistas literais sobre a origem do universo e da vida no planeta. Quase sempre doutrinárias e fundamentalistas, tais visões divergem tanto das explicações evolutivas que obstruem quaisquer possibilidades de abertura a diálogos e ressignificações a partir dos conhecimentos e sistemas de raciocínio científicos.

Examinamos a emergência institucionalizada desse debate quando analisamos algumas das implicações e desafios ao ensino de Ciências e Biologia que emergiram da implantação de uma lei estadual sancionada em 2000, quando tornou obrigatório por parte do Governo do Estado do Rio de Janeiro o ensino religioso na forma confessional (SELLES, DORVILLÉ e PONTUAL, 2016). Para este exame, mobilizamos o conceito de rede discursiva, originada nos trabalhos de Peter Fry (2005). Esta rede discursiva refere-se ao conjunto de discursos produzidos na mídia, nos meios acadêmicos e nos documentos governamentais em torno de um determinado fato social, levando em consideração o contexto social de sua produção.

Os principais objetos empíricos de investigação que trouxemos neste trabalho foram as 
cartas dos leitores do "O Globo"10. Para dialogar com elas na perspectiva da rede discursiva era imprescindível também fazer um levantamento das matérias (reportagens, colunas e notas) relacionadas ao ensino religioso, evolucionismo e criacionismo publicadas neste jornal. Foram encontrados 102 registros, sendo 67 no formato de matérias e 35 na forma de carta dos leitores. Os conteúdos das matérias foram analisados e classificados em três grupos de respostas: "a favor", quando a linha de argumentação era favorável à implantação do ensino religioso confessional; "contra”, quando a apresentação da matéria declarava-se contrária à sua implantação; e um terceiro grupo, que acomodava as matérias que possuíam conteúdo exclusivamente informativo, sem opinião ou tendência expressa.

Ao explicitar no artigo a quantidade representativa de cartas e outras seções da mídia em favor do ensino religioso este debate dirigiu-se também à seleção dos conteúdos e métodos do ensino de Ciências e Biologia. Argumentamos que a interferência política do Estado passou a assumir uma forma de coerção sobre os processos decisórios docentes no tratamento dos conteúdos de evolução no cotidiano escolar. O debate entre criacionismo e evolucionismo voltou então, explicitamente, a ter um caráter institucionalizado, deixando de se travar apenas no domínio do confronto individualizado de ideias, entre sujeitos professores e seus alunos.

Os discursos que argumentam pela presença institucionalizada dos saberes religiosos nos currículos escolares reforçam as concepções de que cabe à escola atuar como um dispositivo para a remissão moral das juventudes ou um antídoto para a crise social. Crise esta que é fruto da falência do modelo societário capitalista quando o mesmo privilegia o lucro em detrimento da vida ou aposta no desenvolvimento a qualquer custo, ignorando os anseios sociais e as emergências climática locais e global.

A julgar pelo desenrolar histórico das décadas posteriores ao ano 2000, a obrigatoriedade do ensino religioso confessional parece ter se localizado em outros territórios disciplinares, pois os conteúdos relativos à origem e evolução humana passaram a ser disputados no currículo da Educação Básica, de modo a tornar equivalentes as bases científicas e as religiosas. A opção de ensinar evolução vem sendo questionada pelo MESP como se as responsabilidades e escolhas das famílias em âmbito privado tivessem se tornado responsabilidade pública do Estado brasileiro.

Como argumentado em diversos estudos (TEIXEIRA, 2019; FALCÃO, 2018; DORVILLÉ e SELLES, 2018), relativizar o ensino das teorias evolutivas equiparando-as aos criacionismos, como se fossem apenas meras teorias, obviamente nega aos estudantes o direito de acesso a uma das explicações científicas de poder heurístico inquestionável e que tem implicações diretas com a visão de mundo da humanidade. Ademais, essa negação desqualifica as pesquisas e a literatura acadêmica da área, as quais vêm fertilizando os cursos de formação docente, a elaboração de livros didáticos e a produção curricular não somente no Brasil, como no exterior.

Com efeito, a ascensão do ultraconservadorismo no Brasil mostra o quanto a polêmica do ensino religioso na escola pública dos anos 2000 no estado do Rio de Janeiro foi associada a novos elementos, incluindo pela primeira vez discussões ligadas não apenas a questões de cidadania e liberdade religiosa, mas também ao debate entre criacionismo e evolução. Este confronto que era relativamente novo no Brasil, mostrou enorme potencial de crescimento desde que o MESP se insurgiu sobre a escola e os professores. Isto se deu como resultado da formação de novas alianças entre grupos religiosos em sua disputa pelo espaço público contra os defensores da laicidade.

Nesse bojo, vale ressaltar que somando-se às iniciativas legais arbitradas pela frente religiosa

10 Tradicional periódico brasileiro publicado desde o século passado de ampla circulação no Brasil. 
conservadora nos espaços legislativos nacionais já apresentadas neste texto, estão os PL 309/2011 e 8.099/2014 propostos por um pastor protestante que é deputado federal. Tais projetos desejam tornar compulsório o ensino de explicações criacionistas em instituições educacionais públicas e privadas. Não obstante, deveria ser conferido o mesmo status epistemológico e destaque dado às teorias científicas. Junto se posiciona o constrangimento promovido pelo MESP que leva professores de Ciências e Biologia a não lecionarem ou a abreviarem o trabalho pedagógico sobre evolução biológica, porque tais conteúdos poderiam se chocar com ideias que circulam no âmbito familiar. Isso exemplifica como uma cultura de auditoria (APPLE, 2015; 2017) tem sido alavancada, afligindo e intimidando a docência comprometido com uma educação cada vez plural, inclusiva, socialmente situada e justa.

Por mais que reconheçamos ser salutar que a escola se configure enquanto espaço de acolhimento, respeito e valorização das diferenças, inclusive no âmbito da prática ou não de crenças e religiões, é necessário tornar esse debate complexo para não cairmos em binarismos ou em armadilhas que fortalecem a ingerência do privado sobre o público e do subjetivo sobre o coletivo. Neste ponto, recuperamos o convite realizado por Apple (2017) para reposicionarmos nossos loci de enunciação, colocando-nos ao lado e no lugar daqueles que são marginalizados e oprimidos pelos discursos e práticas hegemônicas.

Ao considerarmos a constituição democrática de processos educativos como ato político e ético, torna-se preciso sinalizar e criticar desigualdades, além de situar e interpretar relações, contradições e conflitos do poder. Afinal, se um espaço educativo laico não pode admitir comportamentos herméticos e retóricas dogmatizadas, o desafio que se faz presente é a promoção de culturas escolares que aceitem as diferenças e também delas se fortaleçam. A escola deve ser um espaço que possibilite o contato de seus estudantes com diversos modos de pensar e existir no mundo, o que só é possível quando determinadas lógicas, inclusive religiosas, que ensejam as tradições e particularidades que se impõe como totalizantes percam força diante da diversidade de experiências estudantis e docentes. O ensino de Ciências e Biologia pode ser um espaço para que os alunos, em sua variedade de trajetórias e identidades, construam novos conhecimentos e vivências, ampliando as lentes com as quais podem enxergar e decifrar o mundo que os rodeia e a sociedade que os condiciona.

Mesmo assim, como analisamos em exercício prévio (ANDRADE e BORBA, 2018) o ensino religioso foi inserido como área de conhecimento e componente curriculares da BNCC a partir do seguinte entendimento:

Em função dos promulgados ideais de democracia, inclusão social e educação integral, vários setores da sociedade civil passaram a reivindicar a abordagem do conhecimento religioso e o reconhecimento da diversidade religiosa no âmbito dos currículos escolares. A Constituição Federal de 1988 (artigo 210) e a LDB no 9.394/1996 (artigo 33 alterado pela Lei no 9.475/1997) estabeleceram os princípios e os fundamentos que devem alicerçar epistemologias e pedagogias do Ensino Religioso, cuja função educacional, enquanto parte integrante da formação básica do cidadão, é assegurar o respeito à diversidade cultural religiosa, sem proselitismos (BRASIL, 2017, p. 433).

Todavia, examinando o documento legal, encontramos pistas para outras finalidades da inserção do ensino religioso na BNCC que podem induzir colisões com as percepções que circulam dentro do ensino de Ciências e Biologia no que tange ao trabalho com os assuntos controversos expostos neste capítulo: 
No conjunto das crenças e doutrinas religiosas encontram-se ideias de imortalidade (ancestralidade, reencarnação, ressurreição, transmigração, entre outras), que são norteadoras do sentido da vida dos seus seguidores. Essas informações oferecem aos sujeitos referenciais tanto para a vida terrena quanto para o pós-morte, cuja finalidade é direcionar condutas individuais e sociais, por meio de códigos éticos e morais. Tais códigos, em geral, definem o que é certo ou errado, permitido ou proibido. Esses princípios éticos e morais atuam como balizadores de comportamento, tanto nos ritos como na vida social (BRASIL, 2017, p. 438 - grifos nossos).

É impossível não mencionar que a supressão da discussão sobre gênero e o enfraquecimento dos debates sobre sexualidade ocorreu simultaneamente à inserção definitiva do ensino religioso na BNCC, representando duas opções curriculares que se distanciam dos ideais progressistas. Nossa leitura é a de que o fortalecimento do ensino religioso e sua tácita prescrição na composição de um currículo oficial, nacional e unificado é forte indício das tensões históricas entre os domínios público e privado na educação brasileira.

Simultaneamente, se produz o agravamento das recentes incursões do conservadorismo sobre os currículos das disciplinas escolares Ciências e Biologia. Sabemos na história recente da educação brasileira os momentos nos quais o arsenal de saberes religiosos mais pautaram os currículos escolares foram aqueles nos quais os equilíbrios de forças do tabuleiro social se deslocaram em direção ao conservadorismo, representando retrocesso à consolidação de uma educação pública, laica, democrática e de qualidade.

\section{Considerações finais}

Sendo histórica, social e culturalmente produzido, o ensino de Ciências e Biologia pode carregar sentidos e assumir significados distintos de acordo com os sujeitos e as instituições com que dialoga. Por isso, compreendemos que, dentro e/ou fora dos contextos escolares, uma diversidade de conhecimentos e práticas educativas com diversas finalidades é cotidiana e criativamente elaborada e divulgada. Ensina-se Ciências e Biologia, dentre outras coisas, também para que os estudantes desenvolvam um pensamento crítico capaz de problematizar, partindo de suas lógicas e pressupostos próprios, até mesmo versões hegemônicas da própria atividade científica.

Nessa conjuntura em que o neoliberalismo e o conservadorismo se abraçam e caminham de mãos dadas, com apoio de líderes religiosos alinhados ao campo ideológico mais autoritário e de uma classe média que defende regimes administrativos gerencialistas, muitas transformações estão em curso nas disciplinas escolares Ciências e Biologia. A partir da redefinição de políticas e práticas sociais, culturais e educativas de acordo com diretrizes ideológicas que tentam fulminar o caráter progressista dos currículos escolares, aumentando a ingerência do âmbito privado sobre o público e alinhando os sistemas educacionais a interesses particulares e a projetos de grupos sociais restritos (APPLE, 2001; 2017).

Contudo, a produção histórica das disciplinas escolares se dá em um espaço de negociação entre os conhecimentos e as tradições científicas, os saberes oriundos de espaços não escolares, as culturas e os cotidianos das próprias instituições educacionais. Esse diálogo promove intercâmbios, tensões, interpelações e produções que demonstram o dinamismo dos processos de construção do currículo. Diante da intensificação de mecanismos de regulação do trabalho docente - notabilizados pela BNCC e pelos sistemas de avaliação em larga escala que a acompanham - fomentados pelos 
setores gerencialistas e do agravamento de iniciativas refinadas de controle e coerção da ação professoral rumo ao assolamento da escola pelo conservadorismo, bem representada pelo MESP, cabe perguntar: Quais serão as novas relações produzidas entre os conhecimentos científico e escolar com as diferentes culturas que penetram as escolas? Como as políticas de currículo em curso impactarão a formação e a profissão docente na próxima década? Que temas caros ao ensino de Ciências e Biologia continuarão sendo perseguidos por provocarem controvérsias? Haverá algum arrefecimento causado pelos atravessamentos socioculturais que estão presentes nas escolas?

Trazemos essas ponderações porque concordamos com Apple (2017) que os currículos devem considerar as demandas daqueles não enquadrados nos padrões legitimados de classe social, de raça, de sexualidade e de gênero. Além disso, também é função das disciplinas escolares foco desse capítulo se responsabilizar ética e politicamente pela promoção de uma verdadeira transformação social que permita a inclusão de sujeitos que passam por processos de desumanização dentro e fora da escola. Tal responsabilidade, também a cargo de tantas disciplinas escolares, parece recair fortemente sobre os professores de Ciências e Biologia no momento em que abordam aspectos relativos às questões humanas, quando tangenciam as múltiplas manifestações e fenômenos da vida.

Por fim, permanece nosso convite a uma inquieta reflexão face ao cenário que se desenha, uma vez que a influência vigorosa de movimentos conservadores tem insistido que apenas um determinado tipo de conhecimento, considerado "neutro" por assumir uma roupagem que disfarça os posicionamentos e valores hegemônicos, deve ter espaço e voz nas aulas. Qual será o custo a ser pago pela população brasileira, principalmente dentre os mais economicamente vulneráveis, da intensificação dos processos de exclusão de questões culturais que atravessam a constituição plural dos sujeitos, que são biológicos, mas também sociais?

\section{Referências}

ANDRADE, Maria Carolina Pires; BORBA, Rodrigo Cerqueira do Nascimento. 0 golpe, a BNCC e os conservadorismos: pensando o Ensino Religioso na Educação Brasileira. Revista Communitas, v. 2, 2018, p. 121-139.

APPLE, Michael. Reestruturação educativa e curricular e as agendas neoliberal e neoconservadora: entrevista com Michael W. Apple. Currículo sem Fronteiras. v.1, n. 1, 2001, p. 5-33.

APPLE, Michael. Produzindo diferença: neoliberalismo, neoconservadorismo e a política de reforma educacional. Linhas Críticas. Brasília, n. 45. 2015. p. 606-544.

APPLE, Michael. A luta pela democracia na educação crítica. Revista e-curriculum. São Paulo, v. 15, n. 4, 2017. p. 894 - 926.

BASTOS, Felipe; ANDRADE, Marcelo. Cabe discutir gênero e diversidade sexual no ensino de Biologia? In: LIMA-TAVARES, Daniele; VILELA, Mariana Lima; AYRES, Ana Cléa Moreira; MATOS, Maria (Org.). Tecendo laços docentes entre ciência e culturas. 1ed.Curitiba: Prismas, 2016, v. , p. 159183.

BALL, Stephen. Profissionalismo, gerencialismo e performatividade. Cadernos de pesquisa, v. 35, n. 126, 2005, p. 539-564.

BIESTA, Gert. Para além da aprendizagem: educação democrática para um futuro humano. Belo Horizonte: Autêntica Editora, 2013.

BORBA, Rodrigo Cerqueira do Nascimento; ANDRADE, Maria Carolina Pires; SELLES, Sandra Escovedo. Ensino de Ciências e Biologia e o cenário de restauração conservadora no Brasil: inquietações e reflexões. Revista Interinstitucional Artes de Educar, v. 5, 2019, p. 144-162.

BRASIL. Fundo Nacional de Desenvolvimento da Educação. Resolução 42/2012 - Dispõe sobre o 
Programa Nacional do Livro Didático (PNLD) para a educação básica.

BRASIL. Ministério da Educação. Base Nacional Comum Curricular ( $3^{a}$ versão - abril de 2017). Brasília, DF, 2017. 396p.

BRASIL. Ministério da Educação. Base Nacional Comum Curricular ( $3^{a}$ versão revista - dezembro de 2017). Brasília, DF, 2017a. 472p.

CHOPPIN, Alain. História dos livros e das edições didáticas: sobre o estado da arte. Educação e Pesquisa, São Paulo, v.30, n.3, p. 549-566, set./dez. 2004.

DORVILLE, Luis Fernando Marques; SELLES, Sandra Escovedo. Ensino de Evolução e Criacionismo na Educação Básica: ressignificação de um debate em Tempos Sombrios. In: D'AVILA-LEVY, Claudia Masini; CUNHA, Luiz Antonio (Orgs.). Embates em torno do Estado Laico. 1ed. São Paulo: SBPC, 2018, v. 1, p. 131-162.

FALCÃO, Eliane Brígida Morais. Laicidade e Ensino de Ciências: Reflexões sobre o Estudo dos Fenômenos da Vida no Ensino Médio. In: D'AVILA-LEVY, Claudia Masini; CUNHA, Luiz Antonio (Orgs.). Embates do em torno do Estado Laico. 1ed.São Paulo: SBPC, 2018, v. , p. 163-182.

FREITAS, Luiz Carlos. Os reformadores empresariais da educação: da desmoralização do magistério à destruição do sistema público de educação . Educ. Soc. [online]. 2012, vol.33, n.119, pp.379404.

FRY, Peter. O significado da anemia falciforme no contexto da "política"racial do governo brasileiro, 1995-2004. In: A Persistência da Raça. Ensaios antropológicos sobre o Brasil e a África Austral. São Paulo: Mercado das Letras. 348p, 2005.

PENNA, Fernando de Araújo. O Escola sem Partido como chave de leitura do fenômeno educacional. In: FRIGOTTO, Gaudêncio. (Org.). Escola 'Sem' Partido: esfinge que ameaça a educação e a sociedade brasileira. 1ed.Rio de Janeiro: UERJ, LPP, 2017, v. 1, p. 35-48.

SELLES, Sandra Escovedo; DORVILLE, Luis Fernando Marques; PONTUAL, Leandro Vahia. Ensino religioso nas escolas estaduais do Rio de Janeiro: implicações para o ensino de ciências/biologia. Ciência \& Educação, v. 22, p. 875-894, 2016.

TEIXEIRA, Pedro Pinheiro. Acceptance of the theory of evolution by high school students in Rio de Janeiro, Brazil: scientific aspects of evolution and the biblical narrative. International Journal of Science Education, v. 4, p. 1-21, 2019.

VILELA, Mariana Lima; SELLES, Sandra Escovedo. Corpo humano e saúde nos currículos escolares: quando as abordagens socioculturais interpelam a hegemonia biomédica e higienista. Bio-grafía: escritos sobre la biología y su enseñanza, v. 8, p. 113-121, 2015. 